\title{
FASILITAS KEMATIAN BAWAH TANAH : NARASI SEBAGAI PENDEKATAN DESAIN ARSITEKTUR
}

\author{
Deanna $^{11}$, Maria Veronica Gandha ${ }^{2)}$ \\ 1)Program Studi S1 Arsitektur, Fakultas Teknik, Universitas Tarumanagara, dnachia@gmail.com \\ 2) Program Studi S1 Arsitektur, Fakultas Teknik, Universitas Tarumanagara, mariag@ft.untar.ac.id
}

\begin{abstract}
Abstrak
Proses pemakaman dengan membakar jenasah dalam perapian dan krematorium merupakan sebuah metode pemakaman yang sudah diterapkan oleh manusia dari jaman dahulu kala. Generasi millennial pada abad 21 telah mengubah sistem dan teknologi yang ada kearah yang lebih ramah lingkungan dan kustomisasi. Pelaksanaan proses kremasi berbasis hidrolisis dan elektrik ini bertujuan untuk mengurangi pengunaan lahan terbuka sebagai makam dan mengurangi emisi karbon. Keadaan yang saat ini terjadi di DKI Jakarta yaitu adanya konsep fasilitas krematorium yang bersifat meninggal "luxury" dan mengabaikan kematian manusia sebagai siklus yang berbasis pada alam, telah merusak ekosistem. Biaya yang mahal dan proses pemakaman yang terpisah-pisah menjadikan proses pemakaman tidak efisien. Dengan dilakukan perencanaan dan perancangan Fasilitas Kematian Bawah Tanah berbasis pada metode kremasi hidrolisis dan kremasi elektrik di daerah Penjaringan Jakarta utara diharapkan dapat memenuhi kebutuhan proses pemakaman dengan cara millennial yang lebih ramah lingkungan. Menghilangkan kesan traumatik dan menyedihkan menjadi sebuah pengalaman yang membebaskan. Serta menghilangkan batas antara kehidupan kota dan kematian lewat alam sehingga dapat merubah sudut pandangan masyarakat terharap gaya krematorium generasi Milennial yang tidak terkekang oleh waktu.
\end{abstract}

Kata kunci: Hidrolisis; Kremasi Elektrik; Krematorium; Kustomisasi; Milennial; Pemakaman

\begin{abstract}
Funeral process with flammable method and crematorium is a funeral culture that was applied from ancient times until now. Milennial generation as a 21st century most dynamic population has been changing the system and technology towards sustainable future and space customization. The Cremation Proccess based on Hydolisis and Electricity are amied to reduce the use of open land burial and decreasing carbon emission. Situation that is currently occur at DKI Jakarta is the concept of die as luxury and denying human death as a part of natural cycle which destroy the ecosystem and biodiversities. The Expensive amount of luxury funeral service and separated funeral process has made the process becoming inefficient. With the planning and design of Underground funeral parlour facilities based on hydrolysis and electric cremation in North Jakarta, Penjaringan is expected to fulfil the efficient needs of funeral process with millennial eco-friendly way. Eliminating a traumatic and sad impression into a liberating moment for the death. Also, breaking the boundaries between life of the city and death through nature access so it can change the perspective of neighbourhood through timeless crematorium millennial style.
\end{abstract}

Keywords: Electric Cremation; Funeral; Hydrolisis; Crematorium; Customization; Milennial.

\section{PENDAHULUAN}

Setiap generasi selalu mempunyai tantangannya masing-masing. Salah satu tantangan yang generasi milenial harus pikul adalah keterbatasan lahan akibat pembangunan sehingga standar penghijauan kota Jakarta kurang dari 30\% dan lahan penguburan semakin sedikit. Pertumbuhan penduduk DKI Jakarta terus meningkat $10.3 \%$ pertahunnya dan kematian warga juga meningkat $10 \%$ setiap tahunnya menurut Bappenas DKI Jakarta. Karena itu, fasilitas kematian sangat dibutuhkan dan diminati, salah satu solusinya adalah kremasi dalam upaya penghematan lahan terbuka untuk pemakaman. Masalah berusaha ditangani adalah dengan membuat fasilitas kematian di luar kota atau daerah lain. Namun, hal tersebut tentunya akan 
membutuhkan biaya transportasi dan waktu perjalanan yang lebih jauh. Idealnya sebuah kota mencari cara untuk menghidupi kembali lingkungannya dengan menarik kembali populasi yang permanen dari pinggir kota dengan aktivitas sosial dan komunitas seperti hidup bekerja dan menua di kota. Namun, semua hal inklusif dalam siklus kehidupan ini kurang memperhatikan fasillitas kematian di kota. Jaman dahulu, orang-orang lebih menerapkan prinsip lahir, hidup dan meninggal di lingkungan yang ada. Warga mengenal satu sama lain, keluarganya, dan ikatan tersebut lebih bermakna dan kuat.

Beberapa fasilitas kematian yang ada dan berada di pusat kota seperti krematorium cilincing dan heaven cenderung menyeramkan dan menyedihkan. Selain itu, dengan berkembangnya jaman dan modernisasi, krematorium mulai diperindah. Namun, fasilitas yang mewah dan bangunan yang bersifat komersil sulit terjangkau untuk semua kaum dan fasilitas yang ada tepisah-pisah antara kolumbarium, memorial park (berada diluar kota) dan funeral home. Selain itu, proses kremasi yang tidak ramah lingkungan karena asap pembakaran yang menghasilkan emisi karbon dapat meningkatkan pencemaran lingkungan di tengah kota Jakarta yang padat dan bising ini. Evolusi manusia dan peradaban telah membawa dampak pada biodiversitas dan lingkungan secara global. Bahkan setelah kita meninggal, fisikal kita (Sebagai komponen organik seharusnya dikembalikan pada alam untuk memenuhi sikulus ekologikal. Namun, tuntutan ekstra untuk meninggal dengan konsep "luxury" telah mengurangi porsi penting untuk lahan hijau dan ekosistem. Kematian biasanya dilihat sebagai pengalaman traumatik dan pertanda dari kesedihan karena orang terdekat yang meninggal, disaat yang bersamaan merupakan pengalaman yang membebaskan. Kematian adalah sebuah penyatu sosial dan penyetaraan dikarenakan diluar dari berbagai macam agama, ras, status, dan politik, semua orang akan mengalami kematian.

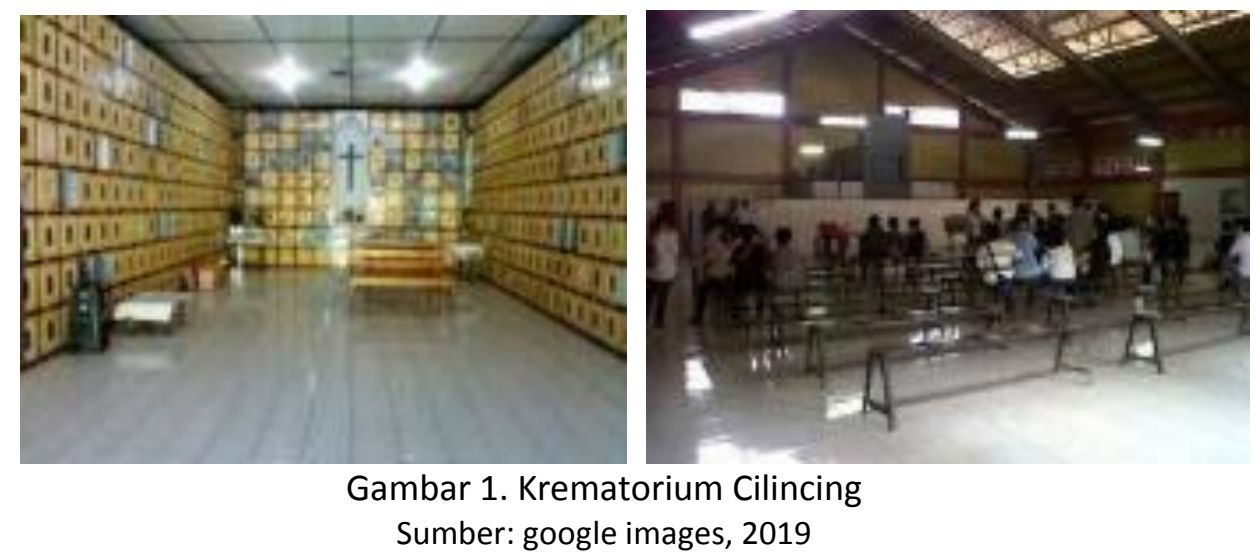

Metode penguburan di jaman milennial ini cenderung berbasis pada konsep sustainabilitas dan efisiensi, berbeda dengan sistem pembakaran kremasi tradisional. Beberapa sistem berbasis teknologi diterapkan guna untuk mengurangi emisi karbon, efiensi waktu, dan memberikan kontribusi terhadap kota. Alternatif dari sistem pembakaran kremasi adalah dengan sistem hidrolisis dan kremasi elektrik. Dalam segi prosesi upacara dan suasana upacara menjadi penting karena millennial adalah sebuah generasi yang tidak konstan. Namun, sebuah generasi yang menyukai hal yang dapat berubah sesuai mood dan kebutuhan mereka.

Maka dari itu, diambil sebuah pemecahan masalah melalui penghadiran sebuah tempat yang menyediakan fasilitas kematian berbasis ramah lingkungan (underground funeral parlour). Tempat ini berusaha mengubah fasilitas kematian yang menyeramkan atau mewah menjadi medium rekonsiliasi antara kematian dan kehidupan lewat alam. Menerapkan ide dasar sebagai simbolisasi bahwa setiap orang yang meninggal akan kembali ke tanah sebagai sebuah rantai siklus kehidupan. Servis akan dilakukan dibawah tanah dan lama kelamaan akan naik ke permukaan tanah melihat penghijauan sebagai simbolisasi kehidupan. 


\section{KAJIAN LITERATUR}

Funeral Parlour menurut kamus besar Oxford adalah sebuah pembentukan tempat dimana orang yang meninggal di preparasi untuk penguburan atau kremasi. Funeral Parlour biasa disebut juga dengan mortuary yaitu sebuah bisnis yang menyediakan instrumen dan servis funeral untuk orang yang meninggal dan keluarganya. Funeral Parlour berbeda dengan Funeral Home dimana Funeral Home biasanya menyediakan fasilitas servis dengan pengalaman memorialisasi dengan skaka yang besar dan fasilitas yang lebih mewah. Mortuary/ Funeral parlour mempunyai hasil yang sama yaitu kremasi. Namun, lebih berkonsentrasi pada penanganan jenasah, mempunyai harga yang relative lebih murah, bersifat langsung, servis yang ada lebih sederhana, dan menyediakan kremasi di dalam tapak.

Menurut salah satu situs edukasi Historia 2017, Kremasi atau pengabuan adalah praktik penghilangan jenazah manusia setelah meninggal dengan cara membakarnya dan biasanya dilakukan di krematorium. Budaya kremasi muncul sejak zaman Yunani Kuno, pada saat itu pembakaran dilakukan di ruang terbuka dan mayat langsung diletakkan diatas tumpukan kayu. Sejak 1000 tahun sebelum Masehi, pembakaran jenazah merupakan kebiasaan umum bangsa Jerman dibuktikan dengan penemuan periuk-periuk berisi abu jenazah dari zaman perunggu. Pada awal abad ke-19, kremasi menjadi populer dilakukan dengan cara modern yaitu proses pembakaran dalam tungku kremasi, dimana jenazah tidak langsung bersentuhan dengan api (Van, 1980).

Kremasi menjadi alternatif penanganan jenazah selain proses pemakaman di sejumlah negara tertentu dengan persentase yang cenderung meningkat setiap tahunnya. Negara Italia misalnya, saat ini 6,5 \% penanganan jenazah di negara tersebut dilakukan dengan cara kremasi, Amerika $27,12 \%$, Inggris $70,70 \%^{2}$ dan negara terbanyak melakukan proses kremasi adalah negara Jepang menurut laporan Nikkei Asian Review 2018, yang hampir 100 \% penduduknya memilih kremasi sebagai pilihan terbaik dalam penanganan jenazah. Tradisi kremasi juga dibawa oleh masyarakat keturunan Tionghoa yang menetap di Indonesia atau biasa disebut dengan Tionghoa peranakan. Akan tetapi, kremasi tidak selalu berarti sebuah metode yang ramah lingkungan dikarenakan pembakaran jasad yang memerlukan gas selama 45 menit yang artinya melepaskan green house gas setara dengan 70.000 kendaraan yang melepas karbon dioksida menurut wawancara Katrina Spade (director dan penemu urban death project) dalam CBC Radio's The Current, 2016.

Tabel 1. Tabel Studi Praktik Penguburan Menurut 4 Agama Utama

\begin{tabular}{|c|c|c|c|c|c|c|}
\hline Burial practice & Catholic & Protestant & $\begin{array}{l}\text { Eastern } \\
\text { Orthodox }\end{array}$ & Islam & Hinduism & Buddhism \\
\hline Ground burial & applicable & applicable & applicable & applicable & applicable & applicable \\
\hline Cremation & applicable & applicable & inapplicable & inapplicable & applicable & applicable \\
\hline $\begin{array}{l}\text { Scattered/ take } \\
\text { cremated ashes }\end{array}$ & inapplicable & applicable & inapplicable & inapplicable & applicable & inapplicable \\
\hline Stacking burial & applicable & applicable & unknown & unknown & unknown & applicable \\
\hline $\begin{array}{l}\text { Non-ground } \\
\text { burial }\end{array}$ & applicable & applicable & applicable & inapplicable & applicable & applicable \\
\hline Sky burial & inapplicable & inapplicable & inapplicable & inapplicable & inapplicable & applicable \\
\hline
\end{tabular}

Sumber: Researchgate.net, 2015

Selain itu, perkembangan kremasi di Indonesia juga dipengaruhi beberapa faktor lainnya:

- Faktor agama, adanya penduduk pemeluk agama dan kepercayaan yang menganjurkan umatnya untuk membakar jenazah sangat mempengaruhi laju perkembangan Krematorium di daerah tersebut. Dapat dilihat dari tabel diatas bahwa kremasi hanya dapat diterapkan kepada agama selain agama muslim. 
- Faktor sosial budaya, secara garis besar, masyarakat Indonesia dapat dibagi menjadi dua kelompok yaitu: kelompok masyarakat komunal yang bersifat tradisional. Kehidupannya sangat dipengaruhi oleh adat istiadat serta menjunjung tinggi nilai-nilai budaya yang sudah dianutnya secara turun temurun. Kedua, kelompok masyarakat modern, mempunyai pola berpikir yang praktis, rasional dan mudah menerima perkembangan dimana ikatan tradisi sudah tidak begitu kuat dalam mempengaruhi cara berpikirnya.

- Secara ekonomi, perhitungan penyelesaian penanganan jenazah dengan kremasi akan jauh lebih murah daripada proses pemakaman. Setelah proses kremasi, semua yang berhubungan dengan jenazah tersebut selesai pada hari itu juga tanpa harus memikirkan uang perpanjangan sewa tanah pemakaman.

- Dikaji dari faktor efisiensi tempat dan waktu, proses kremasi jauh lebih menguntungkan daripada pemakaman biasanya. Dengan proses kremasi, jenazah sudah tidak membutuhkan ruang yang didefinisikan secara horisontal karena yang tersisa hanyalah abu saja. Proses kremasi mulai dari persiapan sampai perabuan rangka hanya memakan waktu 6 jam saja dengan pembakaran normal

Walaupun kremasi membawa dampak positif, salah satunya penghematan lahan, kremasi juga dapat membawa dampak negatif yaitu menghasilkan asap hasil pembakaran yaitu emisi karbon. Beberapa alternatif dari kremasi menurut Sandwell, Anggota West Midlands Council, AS :

\section{- Alkaline Hidrolisis}

Alat ini bisa mengubah mayat menjadi cairan dan abu sisa tulang-belulang. Hasil dari kremasi air ini sangat natural dan bisa menyatu dengan alam tanpa pencemaran. Mayat akan dimasukkan ke dalam tabung, dicampur dengan air dan potassium dan hidroksida. Selanjutnya, larutan alkali akan dimasukan ke dalam tabung bertekanan tinggi ini, dipanaskan hingga 152 derajat celcius. Proses ini memakan waktu 3 jam hingga menjadi abu dan cairan.

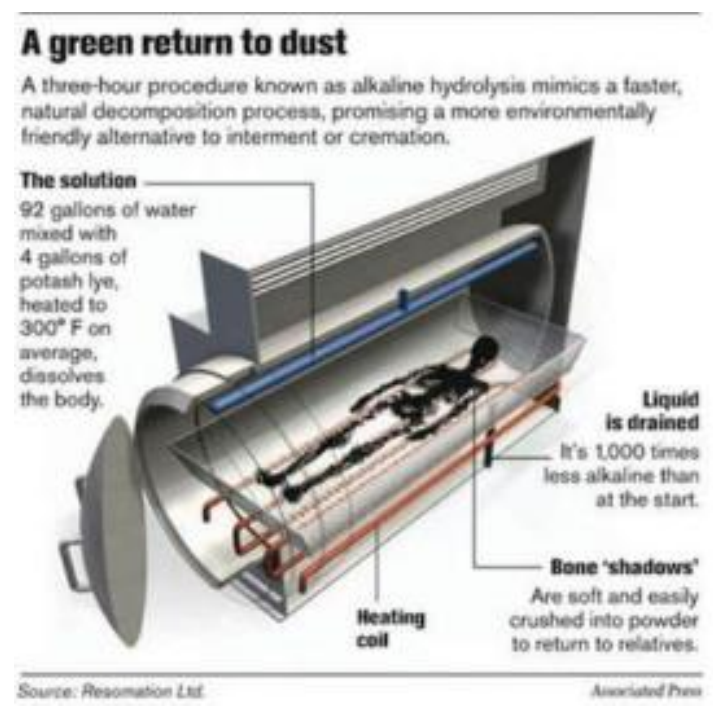

Gambar 2. Krematorium Cilincing

Sumber: google images, 2019

- Kremasi Elektrik

adalah sebuah mesin dimana jasad akan dibakar sampai ketulang, mengeliminasi bagian yang lembut. Kremasi biasa membutuhkan 500-600 kg kayu, $3 \mathrm{~L}$ Kerosin dengan harga yang lebih mahal dan pengambilan abu 24 jam setelahnya. Sedangkan kremasi elektrik 
lebih murah, dapat diambil abunya hanya dengan selang waktu beberapa jam, Tidak ada Kayu yang dibakar dan tidak ada gas emisi.

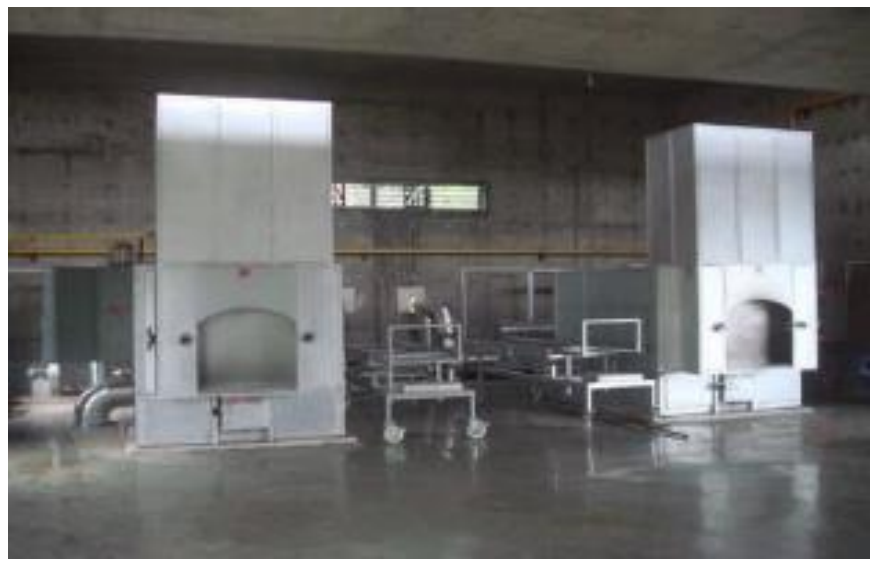

Gambar 3. Krematorium Cilincing

Sumber: google images

Fasilitas lain selain kremasi yang merupakan satu kesatuan dari funeral parlour adalah Kolumbarium dan Rumah berduka. Rumah duka adalah tempat persemayaman jenasah untuk waktu tertentu sebelum melakukan proses pemakaman atau proses kremasi. Kolumbarium adalah ruang yang berfungsi sebagai tempat penyimpanan abu jenasah setelah proses kremasi. Tersedia opsi pelarungan berupa penanaman sebagai nutrisi pupuk (biodegradable urn), penebaran ke laut (ecowater urn), atau disimpan oleh keluarga sendiri. Dalam kacamata milennial yang tidak terpaku oleh hal yang bersifat general, kustomisasi tempat penyimpanan abu atau tempat persemayaman akan membawa suasana yang lebih menyenangkan.

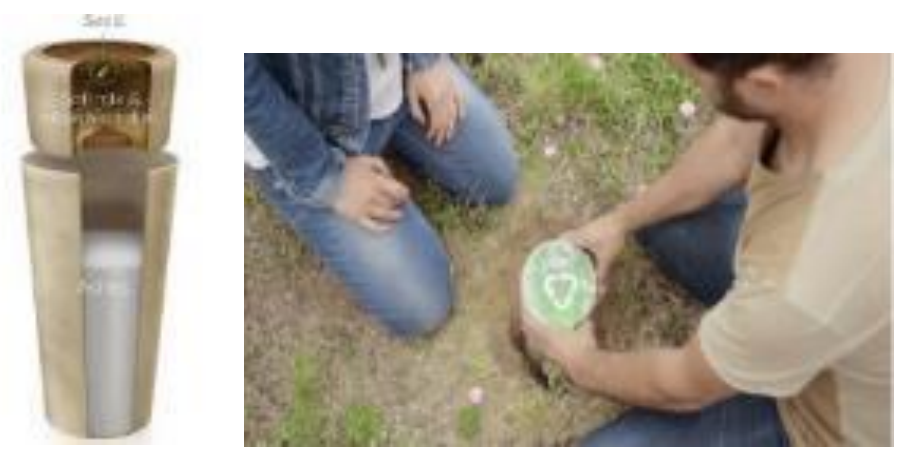

Gambar 4. Biodegradable Urn

Sumber: urnaBios.com

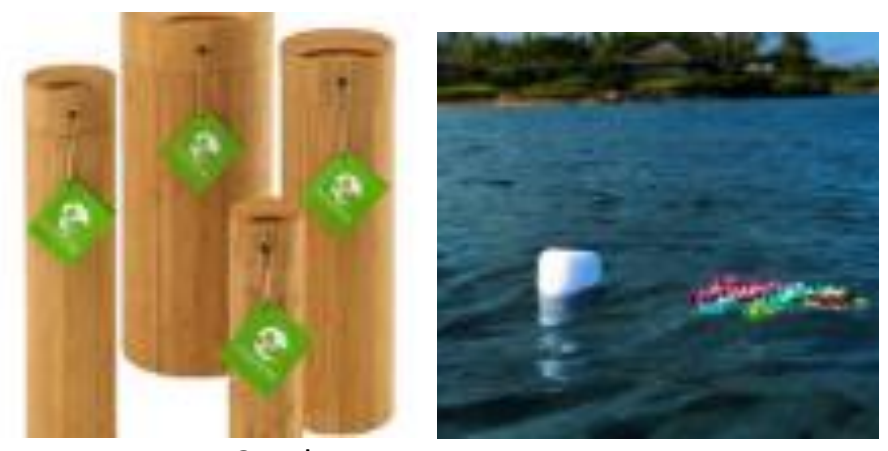

Gambar 5. Ecowater Urn

Sumber: urnaBios.com 


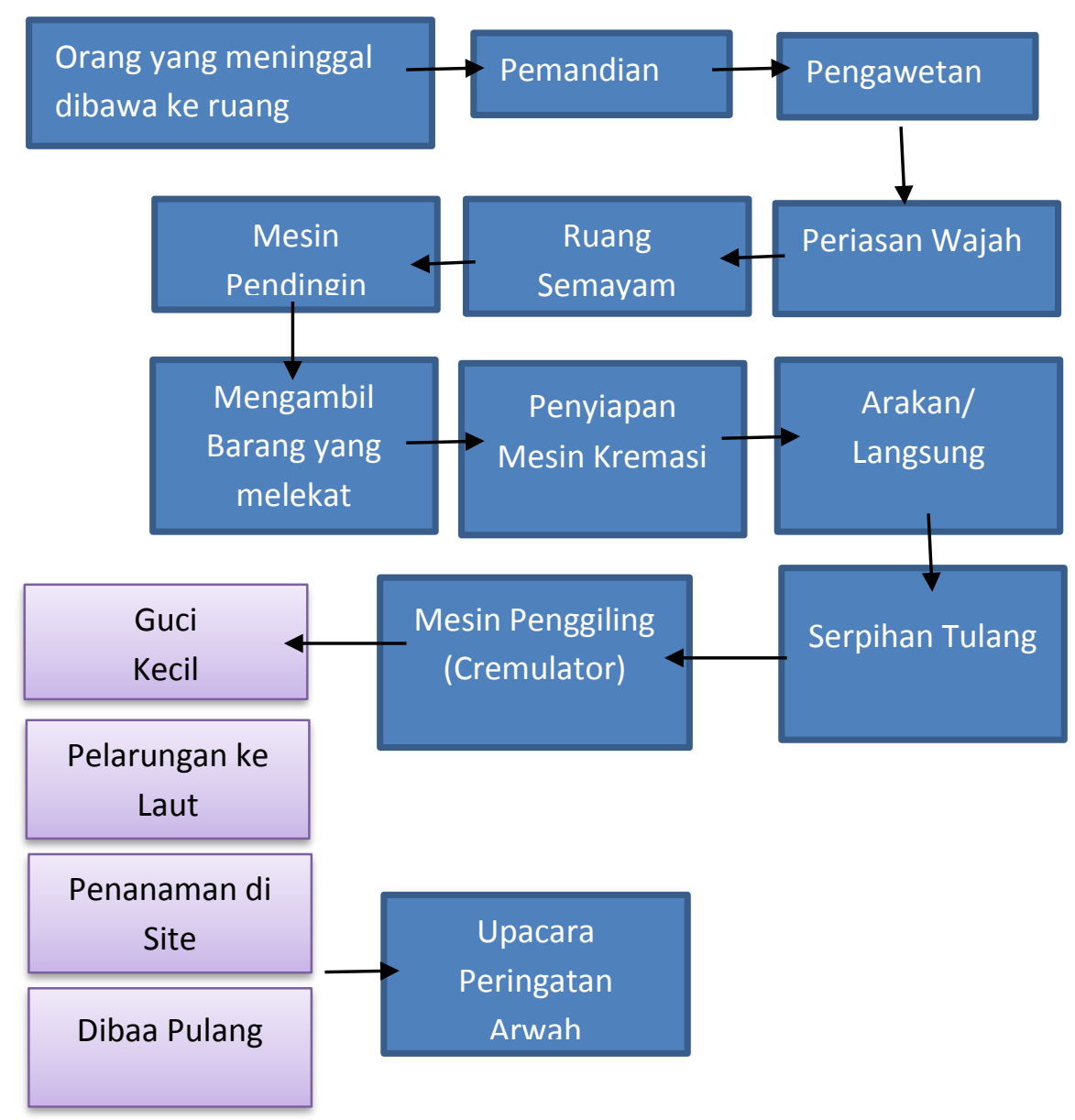

Gambar 6. Skema Kegiatan

Sumber: Penulis, 2019

\section{METODE}

Metode yang digunaan dalam mendesain terdiri dari dua, metode naratif dengan pendekatan dramatisasi dan juga metode yang digunakan dalam melakukan kremasi, berbasis pada sains dan alam :

- Metode Naratif :

Kemampuan untuk memahami identitas dan pandangan dunia seseorang dengan mengacu pada cerita-cerita (narasi) yang ia alami ataupun tuturkan di dalam aktivitasnya. Dengan menggunakan metode naratif maka pendekatan yang dilakukan dalam desain arsitektur adalah dengan mendramatisasi ruang arsitektur sehingga dapat memberikan cerita yang sesuai dengan kehdiupan masyarakat lewat permainan cahaya ataupun sirkulasi. Penerapan metode ini berupa void cahaya, elemen air, diskulasi naik dan turun, dan juga suara.

- Metode Kremasi Ramah Lingkungan :

Metode kremasi Ramah Lingkungan seperti yang sudah dibahas sebelumnya melibatkan alkalin hidrolisis (kremasi dengan air) dan kremasi elektrik. Kedua kremasi yang mempunyai hasil non-karbon emisi ini lebih mudah terurai oleh alam dan memberikan nutrisi terhadap tanaman, dinamakan biodegradable urn . 


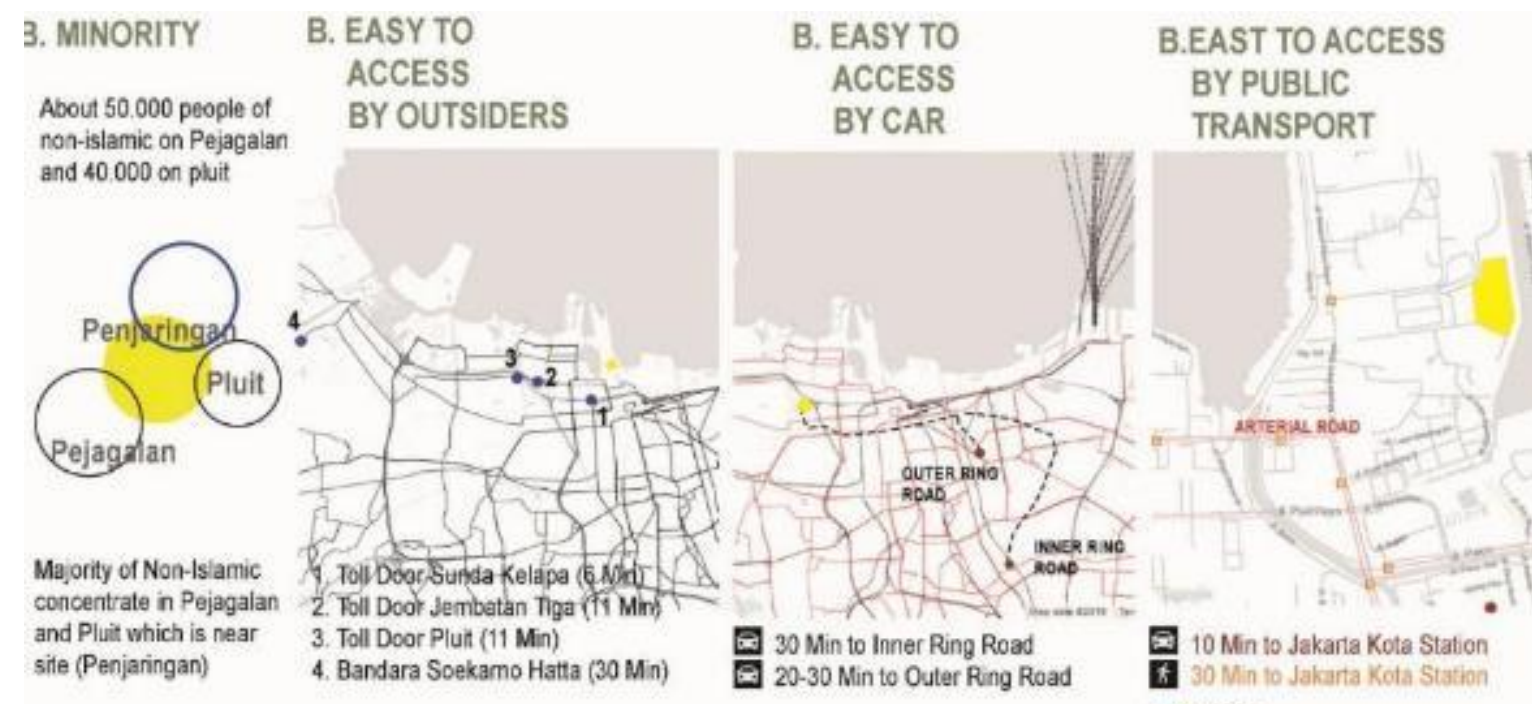

NEAR
HOSPITALS
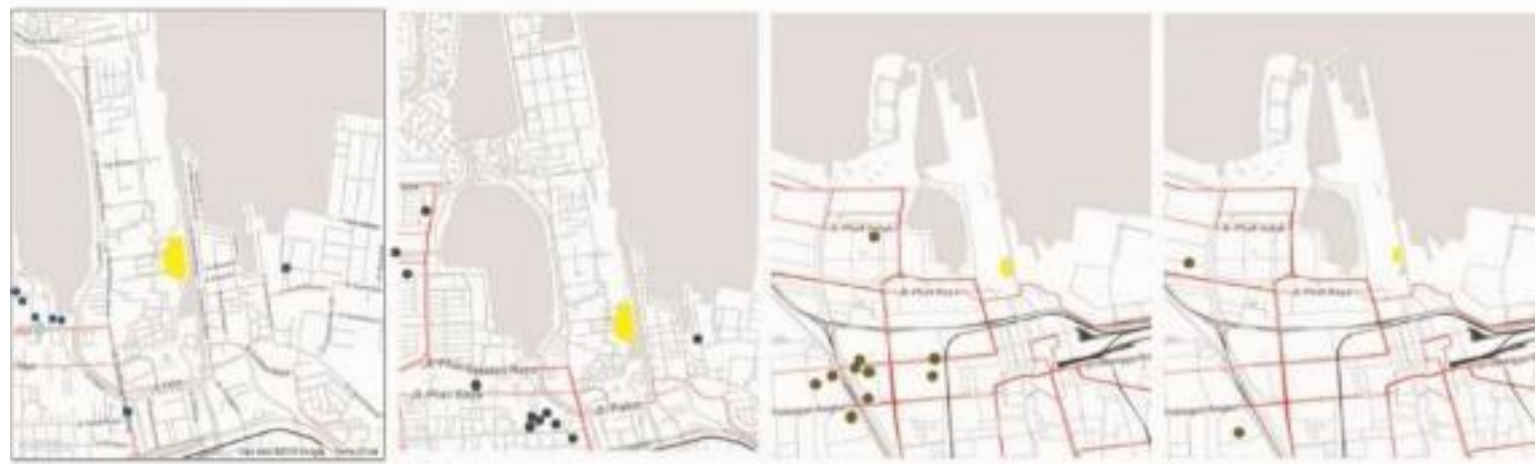

6. 11 Min

F. 8-11 Min

栗 $20 \mathrm{Min}$

mROU NEAREST Crunck
즌 20 Min

nAOU NELREST VILARA
国 11 Min

MROON NEAREST TENPLS

\section{NEAR HARBOUR}

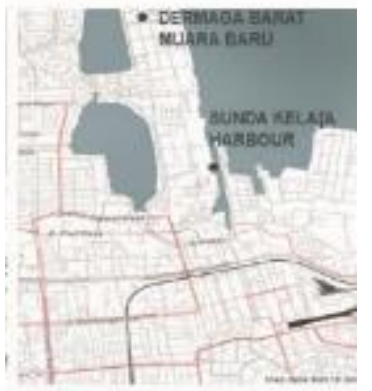

E. 5 Min

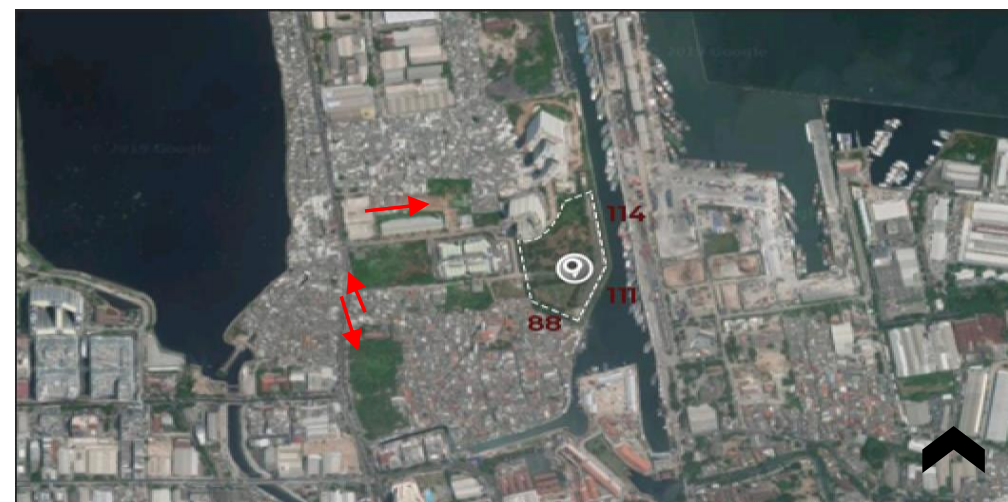

Gambar 7. Analisa Tapak Mikro dan Makro Sumber: Penulis, 2019 

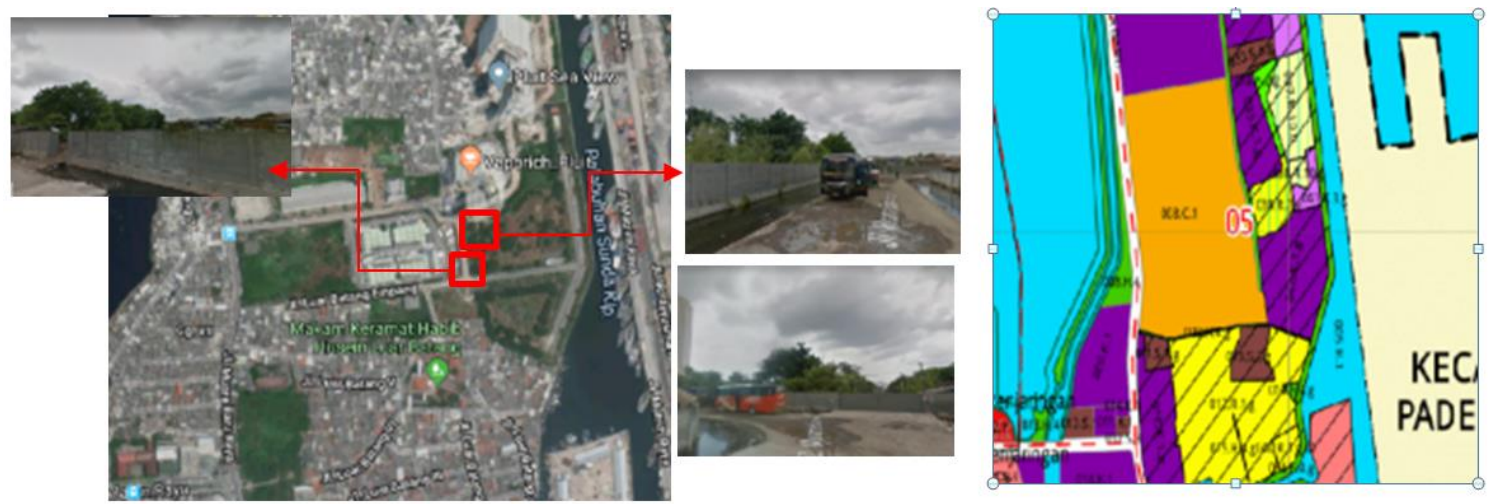

Gambar 8. Kondisi Tapak Sumber: Penulis, 2019

\section{DISKUSI DAN HASIL}

Underground Funeral Parlour atau bangunan fasilitas kematian bawah tanah di Kelurahan penjaringan, Jakarta Utara, Kecamatan penjaringan, tepatnya di Jalan Muara Baru Raya. Proyek ini terdiri dari fungsi-fungsi sebagai berikut: Krematorium terbuka dengan $50 \%$ sistem hidrolisis dan $50 \%$ sistem kremasi elektrik, Ruang Semayam, Kolumbarium tematis, Taman Memorial dengan basis landsekap menurut agama Hindu, Buddha, Kristen, atau general, zona servis pelayanan, akomodasi berupa tempat penginapan untuk keluarga dengan prosesi ritual 3-5 hari, showroom peti atau kotak penyimpanan abu, workshop kustomisasi penyimpanan abu. Area ini memiliki luas sebesar 11.000 sqm termasuk dengan luas basement. Sedangkan untuk area rekreasional dan penunjangnya berupa nature trail, bird observation, Sports Area, Amphitheater, Tea House, Spa\& Saloon, Eating Area, Gathering Area, Florist, dan Minimarket/ATM mempunyai besaran 10.000 sqm. Tidak Lupa bahwa Fungsi ruang yang berada dibawah tanah (Fasilitas kematian) disediakan ruang fan dengan pengudaraan sistem ducting untuk mencegah kelembaban. Berikut merupakan suasana hasil desain :

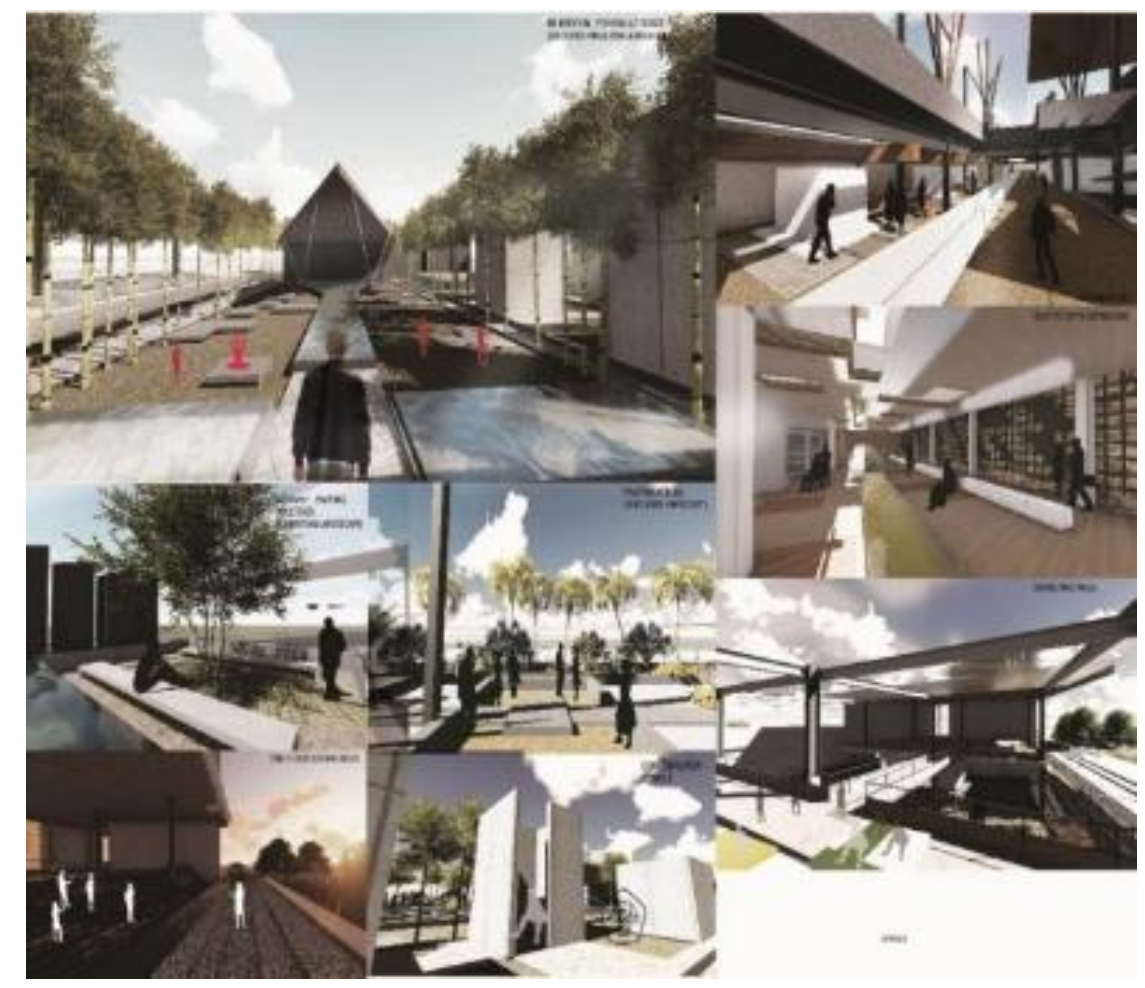

Gambar 9. Interior Bangunan

Sumber: Penulis, 2019 

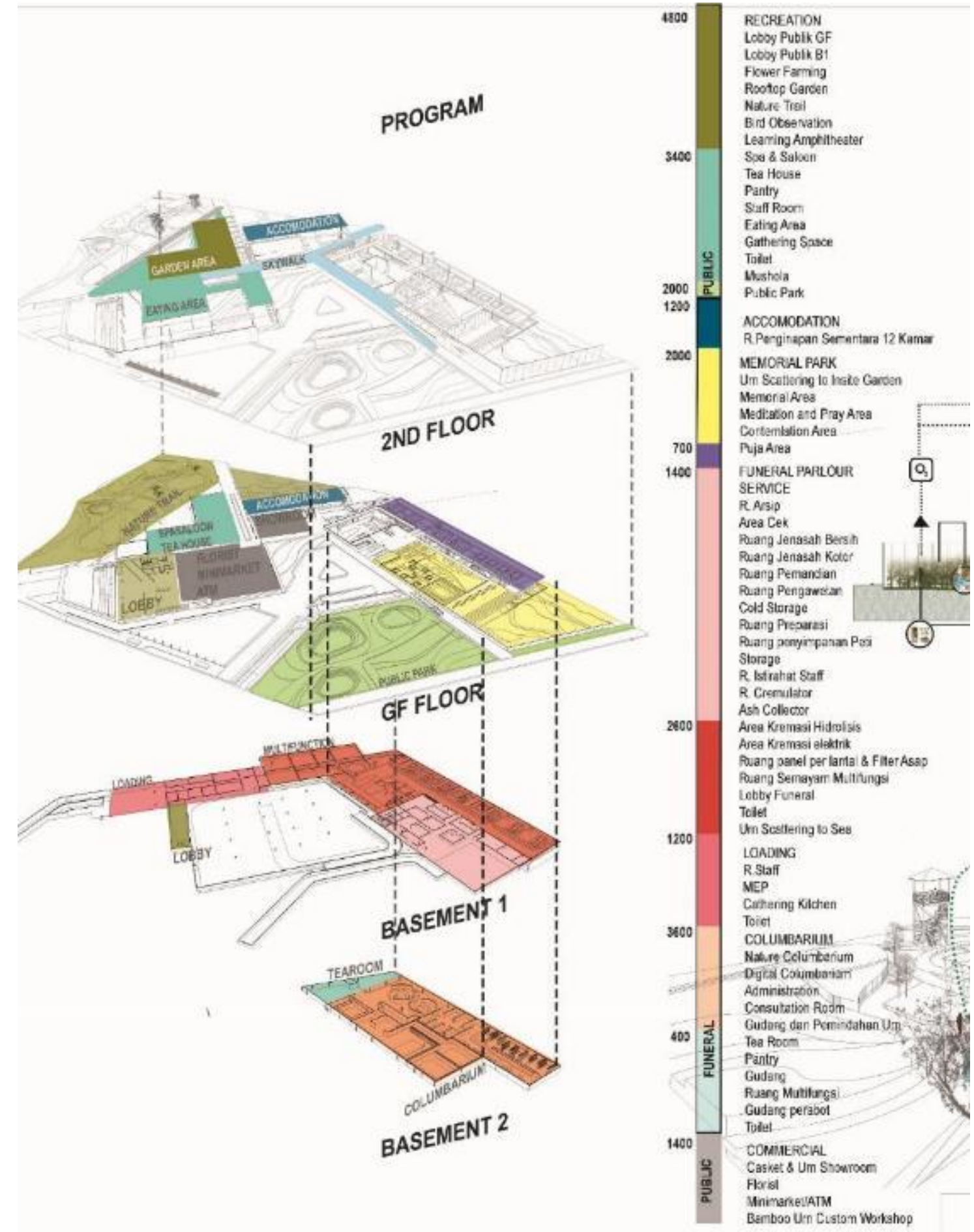

Gambar 10. Zoning Bangunan

Sumber: Penulis, 2019

Disini, program dan desain dibuat dengan basis sustainable. Dimana setiap program yang ada saling menunjang satu dengan yang lainnya. Program showroom peti/ tempat abu dan flowermarket (dijual dari taman bunga dalam tapak) ada sebagai sebuah pendukung dalam menjalankan prosesi ritual dimana keluarga dapat memilih atau mengkostumisasi. Bahan dasar untuk peti/ tempat abu dapat diambil dari pepohonan dan bambu yang dihasilkan dari 
lansekap sekitar dan dapat diolah oleh pengrajin dalam tapak atau diluar tapak sesuai keinginan. Terdapat juga kustomisasi yang bersifat DIY (Do It Yourself) yang dapat dijalankan di area workshop. Sedangkan program komersil dan hiburan seperti spa, refleksi, supermarket adalah program berbayar dalam penyediaan lapangan kerja dan peningkatan ekonomi. Tea house sebagai sebuah ruang teh terbuka publik yang ada sebagai basis kebiasaan orang Tionghoa dalam bersosialisasi dan berkumpul keluarga. Untuk orang yang meninggal dengan opsi penguburan hijau dalam tapak, akan menghasilkan sebuah pohon yang dapat berguna untuk kontribusi oksigen terhadap kota, dalam jumlah banyak dapat mengurangi karbon emisi. Selain itu, meningkatkan kesadaran menanam penghijauan.

Pada aspek lansekap, desain dibuat sesuai dengan adaptasi agama Buddha, Hindu, dan Kristen. Misalnya Buddha dan Hindu identik dengan tanaman seperti bambu, air, dan teratai. Hindu identik dengan tanaman tropikal, dan Kristen identik dengan penyusunan lansekap radial untuk berdoa bersama dan bercerita.
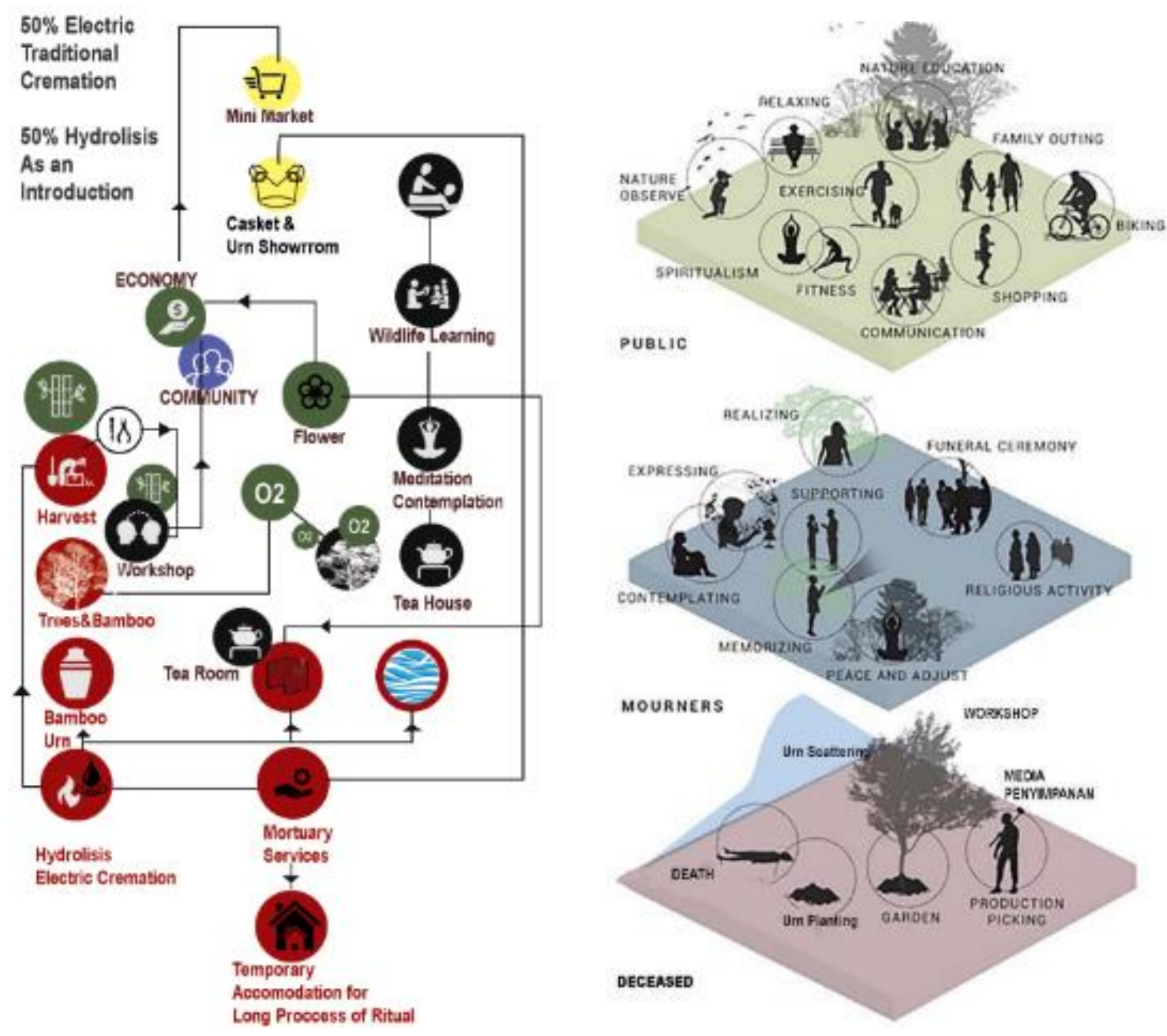

Gambar 11. Sustainable Loop (kiri) dan Tahapan Naratif (kanan)

Sumber: Penulis, 2019 


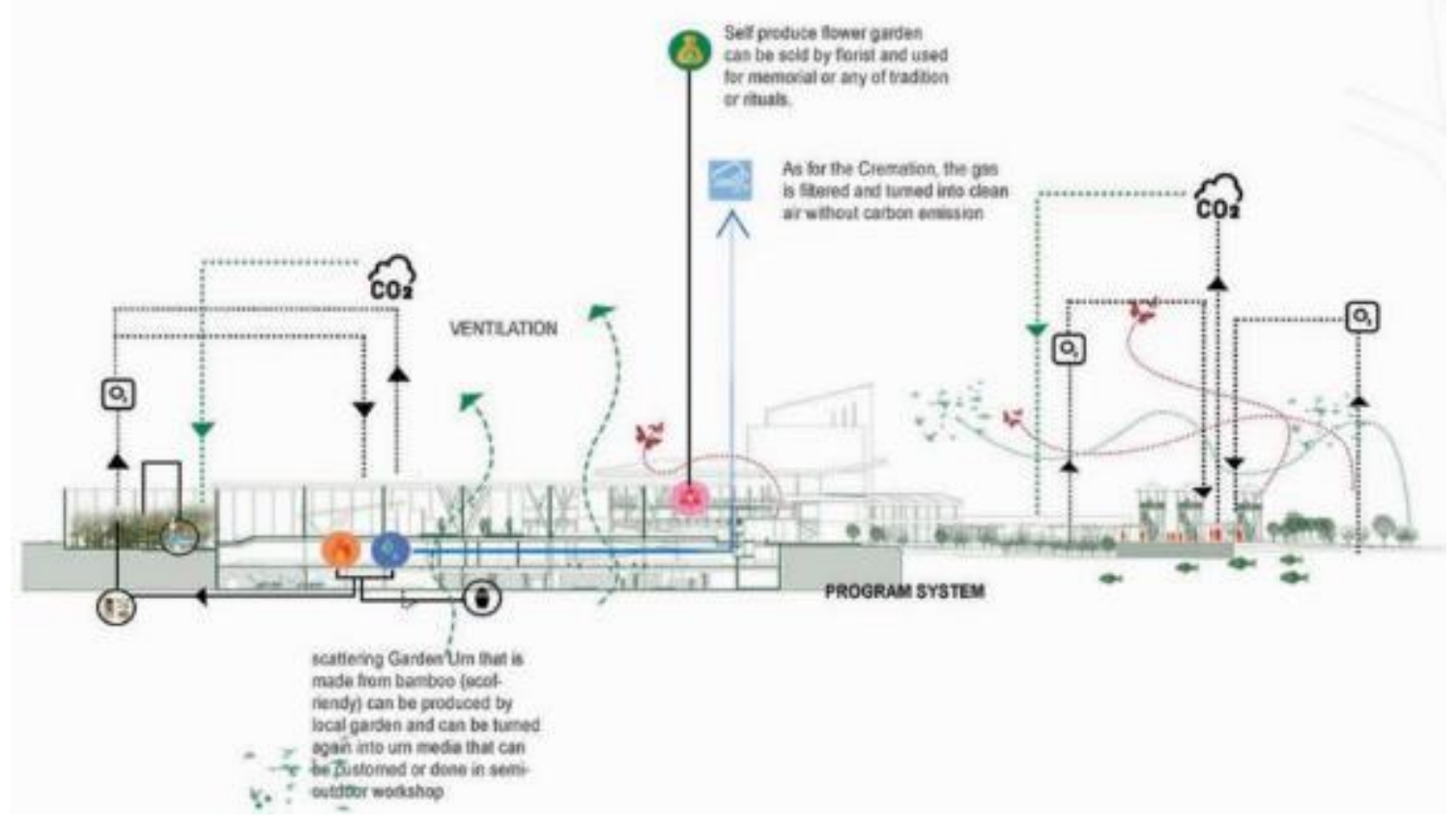

Gambar 12. Sustainable Loop II

Sumber: Penulis, 2019

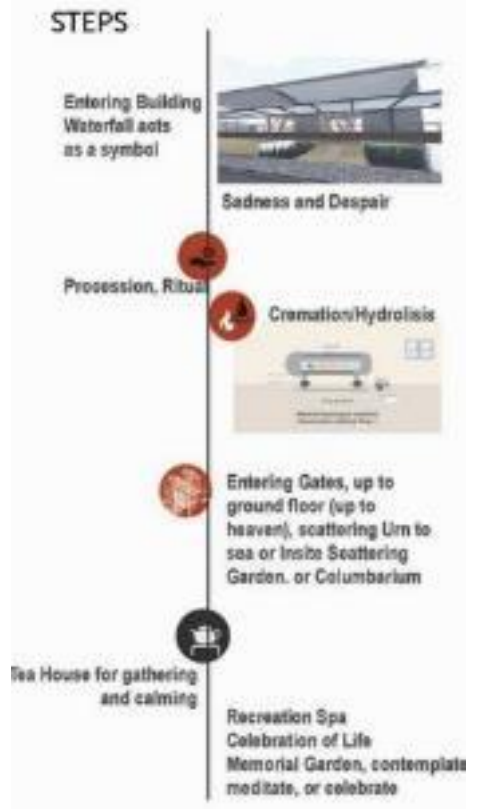

Gambar 13. Tahapan Sirkulasi

Sumber: Penulis, 2019

Dalam segi pendekatan metode naratif, pengunjung akan diajak masuk ke dalam site disambut dengan elemen alam seperti air dan lansekap penghijauan. Suara dan pantulan cahaya dari elemen air berfungsi untuk menenangkan pengunjung yang bersedih dan trauma. Seiring pengujung berjalan kebawah, memberikan perasaan tertekan dan kebisinganpun mulai berkurang. Area menjadi lebih sunyi dan sakral, melihat beberapa kerumunan orang berdoa dan bercerita satu dengan yang lainnya. Cahaya void dari atas memberikan pertanda bahwa 
dalam setiap kegelapan dalam kematian selalu ada harapan. Setelah melakukan segala prosesi ritual, keluarga dan pengunjung dapat melakukan upacara tebar abu ke laut, menaiki sebuah tangga memberikan kesan membebaskan, menuju dermaga sunda kelapa. Yang tidak mau melakukan penebaran dapat menyimpan abu pada kolumbarium yang dihiasi dengan dinding bebatuan coral dan void, memberikan kesan alam walaupun berada dipaling bawah. Opsi lain yaitu menanam abu pada tapak, menjadi sebuah pohon yang dapat memberikan kontribusi oksigen terhadap kota. Setelah itu pengunjung dibawa naik ke atas menuju ke taman rekreasional dan fasilitas hiburan seperti spa, relaksasi untuk meringankan beban pikiran dan menselebrasi siklus kehidupan manusia.

\section{KESIMPULAN DAN SARAN}

Disimpulkan bahwa Fasilitas Kematian Bawah Tanah di Penjaringan ini berperan sebagai wadah metode kremasi ramah lingkungan dengan tujuan meningkatkan biodiversitas kota dan mengurangi emisi karbon berbasis pada konsep milennial yang ramah lingkungan. Disaat yang bersamaan, menghilangkan kesan menyeramkan dan menyedihkan dengan menyediakan fasilitas dan prosesi kematian yang menyatu dengan alam dan taman rekreasional. Disediakan pula landsekap dan pilihan ruang sebagai kostumisasi ala milenial.

\section{REFERENSI}

Beach, G. (2016). Urban Death Project aims to rebuild our soil by composting corpses. Retrieved June 20, 2019, from Inhabitat: https://inhabitat.com/urban-death-project-aimsto-rebuild-our-soil-by-composting-corpses/

Burwinkel, D. (2015). Death and The City. Retrieved April 23, 2019, from Ohio Link: https://etd.ohiolink.edu/

deCocqueau. (2013). Livable Future for The Deceased. Retrieved April 9, 2019, from Designboom: https://www.designboom.com/project/a-liveable-future-for-the-deceased-2/

Elysenty, D. (2015). Perancangan Rumah Duka, Krematorium, dan Kolumbarium di Band. Retrieved May 21, 2019, from Prezi: https://prezi.com/0icdv3tz556m/perancangan-rumahduka-kreematorium-dan-kolombarium-di-band/

Furuto, A. (2012). 'Dance Floor' Recreation and Memorial Park. (SAGRA Architects) Retrieved 2019 20, June, from Archdaily: https://www.archdaily.com/229173/dance-floor-recreationand-memorial-park-sagra-architects?ad_medium=gallery

Goldade, J. (2018). How Baby Boomers and Milennials Differ in Terms of Death Taboo. Retrieved April 30, 2019, from Design Boom: https://www.frazerconsultants.com/2018/04/how-baby-boomers-and-millennials-differ-interms-of-death-taboo/

Gonzalez, D., \& Fernando, A. (2019, April 22). Bosques Underground Funeral Parlor. Retrieved from designboom: https://www.designboom.com/project/bosques-underground-funeralparlor/

Gosselin, V. (2016). Death in Bloom. Retrieved July 15, 2019, from Pasific Rim Magazine: http://kevinmc.info/prm2017/2016/features-2015/death-in-bloom/

Graham, D. (2006). Indonesian Now with Duncan Graham. Retrieved June 9, 2019, from blogger: http://indonesianow.blogspot.com/2006/08/cremation-in-indonesia.html

Koentjaraningrat, P. D. (1987). Manusia dan Kebudayaan di Indonesia. Jakarta: Djambatan.

Lesmana, I. D. (2018). Perancanaan dan Perancangan Krematorium Kontemporer Karawaci.

Retrieved April 22, 2019, from Universitas Budi Luhur:

http://jom.ft.budiluhur.ac.id/index.php/maestro/article/view/71/34

Maia, M. H. (2014). Dramatic Architectures. Portugal: Centro de Estudos Arnaldo Araújo da. . 
Moline, G. (2017). How Technology and Social Media Are Transforming Rituals Around Death. (Bios Urn Environment S.L.) Retrieved April 22, 2019, from biourn.com: https://urnabios.com/technology-social-media-death-grieving/

P.Hariyono, W. (2015, December). Vertical Cemetery. International Conference on Sustainable Design, Engineering and Construction. Netherlands: Science Direct.

Phukan, R. S. (2014). Electric Cremation vs The Traditional Funeral Pyre. Retrieved April 20, 2019, from Mylndia: https://www.mapsofindia.com/my-india/society/electric-cremationvs-the-traditional-funeral-pyre

Van, H. (1980). Ensiklopedi Indonesia. Jakarta: Ichtiar Baru.

Wardhani, M. K , 2016, Perancangan Krematorium Sankhara Anicca,Program S1, Universitas Atmajaya Yogyakarta, Retrieved May 22, 2019, < http://e-journal.uajy.ac.id/10802/. 
